\title{
Urgences
}

\section{Corps ouverts}

\section{Vianney Gallant}

Numéro 14, août 1986

Corps et jouissances

URI : https://id.erudit.org/iderudit/025260ar

DOI : https://doi.org/10.7202/025260ar

Aller au sommaire du numéro

Éditeur(s)

Urgences

ISSN

0226-9554 (imprimé)

1927-3924 (numérique)

Découvrir la revue

Citer ce document

Gallant, V. (1986). Corps ouverts. Urgences, (14), 25-28.

https://doi.org/10.7202/025260ar

Ce document est protégé par la loi sur le droit d'auteur. L'utilisation des services d'Érudit (y compris la reproduction) est assujettie à sa politique d'utilisation que vous pouvez consulter en ligne.

https://apropos.erudit.org/fr/usagers/politique-dutilisation/
Cet article est diffusé et préservé par Érudit.

Érudit est un consortium interuniversitaire sans but lucratif composé de l’Université de Montréal, l'Université Laval et l'Université du Québec à Montréal. Il a pour mission la promotion et la valorisation de la recherche. https://www.erudit.org/fr/ 


\section{Vianney Gallant CORPS OUVERTS}




\section{Corps ouverts}

une sorte de spasme du regard au cerveau corps embrassés

à l'oeil de toutes les langues

herbes de couchant jouant à boucler le triangle

Un souligné plaine ronde

ma main quitte l'autre page

pourtant un moment distancié pour naître à l'autre

plaisir tout aussi liquide

qui aime tout autant qui cherche tout autant le mot du corps accordé au rythme du souffle

un vent curieux dans un voile translucide

à briser les must de toutes les lunes de miel

mièvres

à tout perdre qui ne se reconnaît indivisible dans la symbiose qui cherchent aussi mes yeux ces perles heureuses

quête de pensée autre comme au miroir

et à ta différence

neuve

Corps ouverts

spirale au cerveau à tous points florale

quand l'aube bruine

langue étrangère si perméable au rêve

quand il scande spartiate dans son petit goulag à rêver blanc sur encre bleue

my dear love

une sorte de spasme blanc

à la négritude des éphémérides amoureuses

corps embrassés

à l'oeil de toutes les langues

ces roses jusqu'aux ombres des pores

chairs à parler nu au respir dépouillé des anges

bouches à clin d'oeil fluide

pulpe boréale

herbes de couchant jouant à boucler le triangle 
Regard buvant les lèvres de l'émerveillement il semble qu'elle vienne des petites étoiles éclatées dans sa peau pour de nouvelles cosmogonies

les mains qui griffent des caresses pour en redemander tendre et remercié

comme homme à femme ou dieu à déesse qui ne demandent qu'à naître pleine: libres et lumière qui ne demandent au lacté du soir à cette luminosité poudreuse l'une d'hiver l'autre des sources et des canyons à chaudes coulées et remercié

de femme à homme en gelées sucrées à marées salines framboise salive parfum mystère embruns valsés que les tangos attendent la douce musique du désir la douce violence qui épelle ses hautes notes encore sauvages Corps ouverts

un souligné palme ronde du coeur plaine ronde d'où le coeur jase ses diastoles de prémonition

il demande toute la place pour se prolonger elle demande ce qu'il croit entendre attendre pour un désir d'enfant

elle recommencée demain au karma des gravures ma main quitte l'autre page Corps ouverts

spasmes en mutation dans les pôles

aux dernières gourmandises à raffiner les questions une ponctuation de petites morsures et de cycles poreux qui vrillent jusque dans les os Diogène perd tous ses cheveux blancs pour retourner à la caverne des phosporescences

une ponctuation de petites gerçures my dear love à quelque coin rond dans les replis roses foetus à graver dans sa mouvance rêvée amarrer cet éol de plaisir cafe con leche à l'esprit du silence rond et chaud 
Corps ouverts

corps embrassés longitude

ordonnée en contrepartie des cicatrices qui fondent

comme une huile onctueuse et des jets d'absolu à l'éclair de tes yeux

à l'oeil de toutes les langues

dans les langes à sécher

à la recherche de l'éclatement

Greenwich à voyager nu dans ton centre du monde

ronde éternité

pour renaître au moment distancié à la fusion du plaisir

de toutes les pages

ton ventre

Coeurs ouverts

de longitude blanche

coeurs embrassés

à l'âme qui s'invente goûte

aux lèvres stellaires

qui chercheraient la rondeur des ombres

et ce qui vient du dedans correspondre

à tous les gestes

jusqu'aux voyelles

du baiser

du baiser

pour se suspendre agile

à tous les bouts du monde 